\title{
ANALYSIS OF SPECIALIST MEDICAL RESCUE TEAM INTERVENTIONS IN SOKOKÓW COUNTY IN 2016
}

\author{
Lukasz Czyzewski ${ }^{11}$ 2, 3 , Artur Karpiarz ${ }^{4}$, Paweł Panasewicz ${ }^{4}$, Krzysztof Izdebski ${ }^{4}$, \\ Grzegorz Moczulski ${ }^{4}$, Marek Koźluk ${ }^{4}$, Dominik Czarnocki ${ }^{4}$ \\ ${ }^{1}$ Department of Nephrology Nursing, Medical University of Warsaw, Warsaw, Poland \\ ${ }^{2}$ Faculty of Health Sciences, Collegium Mazovia Innovative University, Siedlce, Poland \\ ${ }^{3}$ Department of Anaesthesiology, Cardinal Wyszynski National Institute of Cardiology, Warsaw, Poland \\ ${ }^{4}$ Student of Faculty of Health Sciences, Collegium Mazovia Innovative University, Siedlce, Poland \\ Name of the department and institution in which the work was done: Faculty of Health Sciences, \\ Collegium Mazovia Innovative University, Siedlce, Poland
}

\begin{abstract}
INTRODUCTION: One of the main aims of the Polish Emergency Medical Services (EMS) is to rescue and protect human health and life. The aim of the study is to analyze specialist medical rescue team (S MRT) interventions in the county of Sokołów in 2016.
\end{abstract}

METHODS: A retrospective analysis of 1361 ambulance call reports from the period January $1^{\text {st }}$ to December $31^{\text {st }}$ 2016 of rescue activities performed during interventions by S MRTs in Sokołów county.

RESULTS: The mean time of arrival of S MRTs to the patient was $9.42 \pm 7.5 \mathrm{~min}$ (max time is $49 \mathrm{~min}$, min time is 1 minute). Average departure time was $51.8 \pm 23.5 \mathrm{~min}(\max 218 \mathrm{~min}, \mathrm{~min} 23.5 \mathrm{~min}$ ). The highest incidence of S MRTs operations was observed in July $(n=134,10 \%)$ and lowest in February $(n=95,7 \%)$.

CONCLUSIONS: Emergency Medical System reaction time for patients in our region does not differ from other data available in the literature.

KEY WORDS: emergency medical system, medical documentation, Sokołów county, resuscitation, paramedic

Disaster Emerg Med J 2017; 2(3): 107-111

\section{INTRODUCTION}

The Polish Emergency Medical Services (EMS) system is organized under the State Emergency Medical Service Act of 8 September 2006 [1]. One of its main aims is to rescue and protect human health and life.

The effectiveness of rescue interventions, and thus the survival of the patients, is determined by: (1) the timely delivery of the appropriate medical rescue team (MRT) by the medical dispatcher; (2) the dispatch time, in emergency mode (code 1 - up to 60 seconds), urgent (code 2 - up to 120 seconds); (3) the time from ambulance departure to arrival (in cities up to 8 minutes, outside cities up to $15 \mathrm{mi}$ nutes).
Article 36 of the State Medical Rescue Act [1] outlines that medical rescue teams are divided into:

1) specialist medical rescue teams (S MRTs) of at least 3 persons authorized to conduct emergency medical services, including a system physician and a system nurse or a paramedic;

2) basic medical rescue teams (B MRT) consisting of at least two persons authorized to perform medical emergency services, including a system nurse or a paramedic.

$S$ MRTs provide immediate assistance at the incident site to patients in a state of a sudden health and life threatening condition and to victims who are in need of health care (emergency department, 


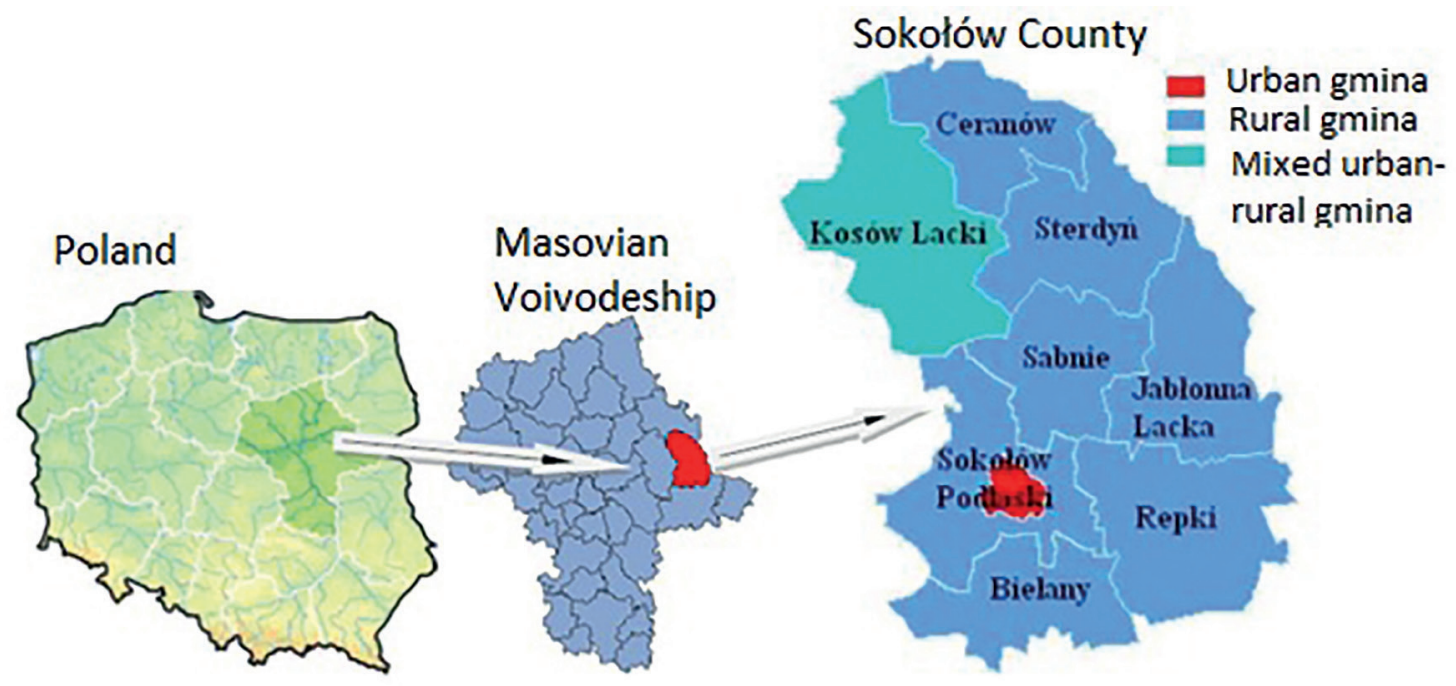

FIGURE 1. Location of Sokołów county [own modification] [2]

emergency room, trauma centre) and which are usually the first of the syndromes in alarm code 1 . The main aim of S MRTs is to carry out the tasks of the "S", "B" and AMR Air Ambulance. A condition for effective EMS is the "golden hour" (the time from the event to the beginning of the specialist treatment) and the Platinum Ten (the time from the onset of the event to the beginning of the MRT).

The aim of the study is to analyze "W 04-51" S MRT interventions in Sokołów county in 2016.

\section{MATERIALS AND METHODS}

The retrospective analysis of 1361 ambulance call reports from the period January $1^{\text {st }}$ to December $31^{\text {st }}$ 2016 of rescue activities performed during interventions by the "W 0451" S MRT in Sokołów county. Exclusion criteria were calls with no patient on the scene, cancelation of calls by the dispatcher and inter-hospital transportation. The survey conformed to the principles outlined in the Declaration of Helsinki. All data were analyzed anonymously with no possibility of identifying individual patients.

Sokołów county is located in the central-eastern part of Mazovia, the largest province in terms of area in Poland. Indeed, its surface area is $1131.17 \mathrm{~km}^{2}$ (2014), which accounts for $3.2 \%$ of the province area, placing it 13 out of 37 counties in the province. In terms of administrative structure, Sokolów county is divided into 9 communes - 1 city commune (Sokołów Podlaski), 1 town commune (Kosów Lacki) and 7 rural communes (Bielany, Ceranów, Jabłonna Lacka, Repki, Sabna, Sokołów Podlaski and Sterdyń) which are divided into 233 villages (Fig. 1). Sokolów county is inhabited by 55,424 people (2014), which when placed in an area of $1131.17 \mathrm{~km}^{2}$, gives a population density of 49 persons $/ \mathrm{km}^{2}$. Although this value is 3 times lower than province of Mazovia, this is due to the large excess of the population density ratio through the large urban centres of the province and the cities in the immediate vicinity (suburban areas), i.e.: Warsaw, Radom, Wołomin and Płock [2].

Operational departure cards were assessed after obtaining the consent of the Director of "RM MEDITRANS" Rescue and Emergency Transport Station in Siedlce. The analysis considered the following parameters: (1) urgency code; (2) time of arrival to the a site of event; (3) order execution time; (4) number of arrivals per month; (5) location of the call point; (6) location of patient transport (hospitals); (7) mortality before the arrival of S MRT; (8) group characteristics in terms of age and gender; (9) performed resuscitation; and (10) performed teletransmission.

\section{STATISTICAL ANALYSIS}

Results concerning quantitative variables were presented as average values \pm standard deviation. Qualitative variables (age, sex) were presented as quantity (n) and percentage values of the whole group (\%) while proportions in groups were assessed with a Chi-squared test. Statistica 13.1 software (StatSoft Inc., Tulsa, OK) was used in the statistical analysis. $\mathrm{P}<0.05$ was adopted as the level of statistical significance. 


\begin{tabular}{|l|c|c|c|c|}
\hline \multicolumn{1}{|c|}{ Table 1. General characteristics of patients transferred to hospitals } \\
\hline \multicolumn{1}{|c|}{ Transported to: } & N & Time 1 [min] & Time 2 [min] & Age [y] \\
\hline Sokołów Podlaski Hospital & 1015 & $9.7 \pm 7.6$ & $48.7 \pm 18.7$ & $60 \pm 24$ \\
\hline Provincial Hospital in Siedlce & 85 & $8.1 \pm 7.1$ & $94.8 \pm 18.0$ & $50 \pm 24$ \\
\hline Siedlce City Hospital & 29 & $9.9 \pm 10.0$ & $95.4 \pm 19.7$ & $42 \pm 17$ \\
\hline Węgrów Hospital & 16 & $16.1 \pm 5.2$ & $61.2 \pm 13.6$ & $63 \pm 20$ \\
\hline AMR Air Ambulance & 6 & $13.8 \pm 7.3$ & $86.7 \pm 70.1$ & $46 \pm 17$ \\
\hline Stayed at home & 210 & $8.1 \pm 6.8$ & $41.8 \pm 19.6$ & $59 \pm 20$ \\
\hline Entire group & 1361 & $9.4 \pm 7.5$ & $51.8 \pm 23.5$ & $59 \pm 23$ \\
\hline
\end{tabular}

\section{RESULTS}

The research group consisted of 683 men (50.2\%) and 678 women $(49.8 \%)$. The mean age of the whole group was $59 \pm 23$ years, men 56.5 years and women 62.8 years $(P<0.001) .603(44.3 \%)$ interventions concerned patients over 65 years of age. There were 55 patients under 16 years of age (4.0\%). The mean time of arrival of $S$ MRTs to the patient was $9.42 \pm 7.5 \mathrm{~min}$ (max. $49 \mathrm{~min}$, min. 1 minute). The average departure time was $51.8 \pm 23.5 \mathrm{~min}(\max .218 \mathrm{~min}, \mathrm{~min} .23 .5 \mathrm{~min}$ ) (Tab. 1).

In 1,151 cases (85\%), medical interventions ended with patient transport to a hospital for further diagnosis and treatment (Tab. 1). The highest incidence of S MRT operations was observed in July $(n=134,10 \%)$ and lowest in February $(n=95$, 7\%) (Tab. 2).

In 593 interventions (43.6\%) the S MRT arrival time was longer than 8 minutes (Table 3 ).

\begin{tabular}{|l|c|l|}
\hline \multicolumn{3}{|c|}{ Table 2. S MRT interventions per month } \\
\hline Month & N & $\%$ \\
\hline January & 132 & 9.7 \\
\hline February & 95 & 7.0 \\
\hline March & 119 & 8.7 \\
\hline April & 118 & 8.7 \\
\hline May & 110 & 8.1 \\
\hline June & 117 & 8.6 \\
\hline July & 134 & 9.8 \\
\hline August & 102 & 7.5 \\
\hline September & 103 & 7.6 \\
\hline October & 105 & 7.7 \\
\hline November & 108 & 7.9 \\
\hline December & 118 & 8.7 \\
\hline
\end{tabular}

Code 1 arrivals were statistically performed more frequently in patients over 65 years $(P<0.001)$. Among patients over 65 years, S MRT interventions resulted in 517 (45.0\%) patients being transported to hospital (Tab. 4).

The relationship between the location of patient transport (hospital) and the time of S MRT arrival was statistically significant $(9.66 \pm 7.61$ vs. $8.08 \pm 6.80$, $\mathrm{P}=0.005$ ) (Fig. 2).

The order execution time was also statistically significant $(53.70 \pm 23.74$ vs. $41.80 \pm 19.55, \mathrm{P}<0.001)$ (Fig. 3). Age had no effect on the increased risk of patient transport to hospital ( $59.1 \pm 23.8$ vs. $59.3 \pm 19.6$ years, $\mathrm{P}=0.926)$.

In the case of 77 interventions (5.6\%), death occurred before the arrival of the S MRT. In the described situation, the time of commencing S MRT intervention did not differ statistically from the time of arrival to other interventions. A statistically sig-

\begin{tabular}{|l|c|c|c|}
\hline \multicolumn{4}{|c|}{ Table 3. Urgency code of ambulance response } \\
\hline & Code 1, N=595 & Code 2, N=766 & $P$ \\
\hline $\begin{array}{l}\text { Time of } \\
\text { arrival }\end{array}$ & $8.69 \pm 6.84$ & $9.98 \pm 7.95$ & $<0.001$ \\
\hline $\begin{array}{l}\text { Order } \\
\text { execution } \\
\text { time }\end{array}$ & $52.11 \pm 24.02$ & $51,64 \pm 23.15$ & 0.712 \\
\hline Age & $53.94 \pm 24.24$ & $63.23 \pm 21.40$ & $<0.001$ \\
\hline
\end{tabular}

Table 4. Distribution of the research group taking
age ranges into account
\begin{tabular}{|l|c|c|c|}
\hline & Age $<65$ & Age $>65$ & $P$ \\
\hline Code 1 & $394(66.2 \%)$ & $201(33.8 \%)$ & $<0.001$ \\
\hline Code 2 & $364(47.5 \%)$ & $402(52.5 \%)$ & \\
\hline Hospitalization & $632(55.0 \%)$ & $517(45.0 \%)$ & 0.232 \\
\hline
\end{tabular}




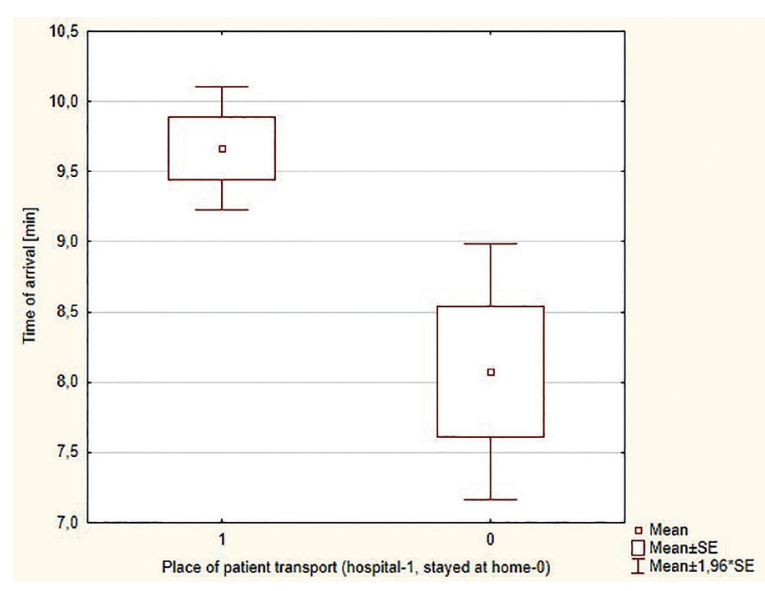

FIGURE 2. Relationship between location of patient transport (hospital) and time of S MRT arrival

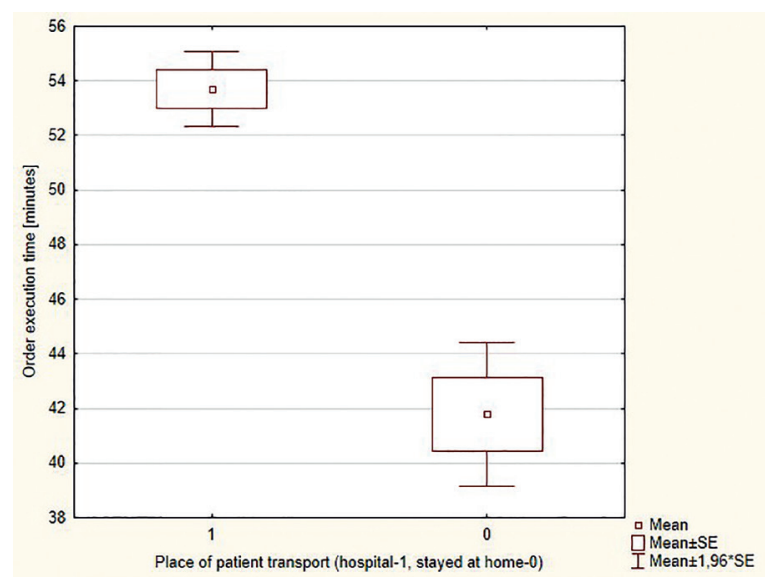

FIGURE 3. Relationship between location of patient transport (hospital) and order execution time of S MRT

nificant shorter duration of departure was reported in the case of death before treatment by $\mathrm{S}$ MRT $(42.5 \pm 16.4$ vs. $52.4 \pm 23.8, \mathrm{P}<0.001)$.

In this study group, the sex of the patient did not affect the time of arrival $(9.3 \pm 7.3$ for men vs. $9.6 \pm 7.8, P=0.555)$ or the time of departure $(52.6 \pm 24.6$ for men vs. $50.9 \pm 22.1, P=0.194)$. Resuscitation was performed in 26 cases (2.0\%). In case where S MRT was performed at the site of occurrence, the duration of follow-up was statistically significantly longer $(74.1 \pm 21.7$ vs. $51.4 \pm 23.4, \mathrm{P}<0.001$.) Age did not affect the frequency of resuscitation performed by S MRT $(62.0 \pm 15.5$ vs. $59.1 \pm 23.3, P=0.535)$, arrival time $(r=0.129, P<0.001)$ or the time of departure $(r=-0.010, P=0.700)$. In urban areas $(N=643)$, the travel time of S MRTs was statistically significantly shorter than that of arrivals outside the city of Sokołów $(\mathrm{N}=718)(3.7 \pm 2.3$ vs. $14.5 \pm 6.9$, $P<0.001)$. In the case of teletransmission ( $N=59$,
$4.3 \%)$, the time of departure was statistically significantly longer compared to those without teletransmission $(71.3 \pm 30.5$ vs. $51.0 \pm 22.8, \mathrm{P}<0.001)$.

\section{DISCUSSION}

The determinant of effectiveness of EMS is to reduce early mortality rates. One of the most important elements of the functioning of EMS is arrival time. Our results are comparable to those of the available literature.

In a study conducted by Gawełko et al. [3] regarding changes in the profile of calls of the Emergency Medical Teams of the Provincial Emergency Service in Rzeszów during the period 2010-2013, in a group of 87,580 patients a death rate of $2 \%$ $(1,838)$ was reported, of whom $1,414(75 \%)$ died before ambulance arrival, 409 (22\%) died during the performance of emergency medical services, and $15(1 \%)$ died during transportation. In the above-cited work, it was shown that 75,858 (88\%) of emergency interventions were deemed code 1 and $10,722(12 \%)$ code 2 . In our study the number of deaths were 91 (6.6\%) of whom 77 (85\%) deaths occurred prior to the commencement of S MRT. No death was reported during patient transportation.

The work of Tamowicz et al. [4] on the causes of resuscitation ambulance calls in the period 2005-2006 in the activities of the Provincial Hospital in Poznań has been shown that of 562 cases, 317 (56\%) were interventions conducted on men, and 245 (44\%) on women. The average duration from the emergency call to the arrival of an ambulance was 14.2 minutes in 2005 and 19.2 min in 2006. In our own research, 776 (57\%) patients were male and 585 (43\%) were female. The duration of ambulance arrival was 9.4 minutes on average. According to the authors, the difference in commuting time to the patient was due to distance, traffic intensity and built-up areas.

In the work of Andrzejewski et al. [5] on the evaluation of the functioning of MRT, the locations of patient transport due to the patient's condition and the transport times at the Widawa substation and the Mickiewicz substation in Łask-Łódź were analyzed. Out of 1087 MRTs, 302 patients (27.8\%) were transported to accredited hospital emergency wards, 368 (33.9\%) to emergency rooms, while 417 (38.4\%) did not provide consent for hospitalization. In relation to the place of occurrence (urban areas and their outskirts), most departures (72.9\%) concerned an urban area. 
In the work of Timler et al. [6], the authors carried out a retrospective analysis of 6,872 EMS operational deoarture cards from 2009 year. in Otwock county. The above-cited study group was comprised of 3,046 (44\%) patients over 65 years of age. In this group, $79 \%(n=2400)$ of medical interventions ended with patient transportation to hospital. The results of our own research indicate a much less frequent transportation of patients to hospital ( $n=517,45.0 \%)$. In Timler's study, the mean time of arrival of MRT to patient was $9.39 \pm 6.87 \mathrm{~min}$, the maximum time being 127 minutes. In our own study, mean arrival time was $9.42 \pm 7.5$ min (max. 49 min., min. 1 min.).

This study has some limitations. Firstly, compared to the other studies, our sample was quite small. Secondly, the fate of the patients was evaluated only until hospital admission.

In conclusion, our data indicates that: (1) Emergency Medical System reaction time for patients in our region does not differ from other data available in the literature. (2) This paper is of interest to workforce planners. We hope it provides important information to paramedics that should facilitate the maintenance of a successful and effective paramedic service.

\section{ACKNOWLEDGMENTS}

The authors are very grateful to Leszek Szpakowski, the Director of "RM MEDITRANS" Rescue and Emergency Transport Station in Siedlce for making ambulance call reports available.

Conflict of interest: None declared.

\section{REFERENCES}

1. State Emergency Medical Service. Journal of Laws 2006.; 191 pos. 1410. Act of 8 September 2006.

2. Development Strategy for the Sokołowski County for the years 2016-2025. Study: Lower Silesian Center for Local Development — Wroclaw.

3. Gawełko J, Wilk K. Analysis of changes in the profile of calls to Emergency Medical Teams at Regional Ambulance Station in 2010-2013. Prz Med Uniw Rzesz Inst Leków Rzeszów. 2015; 13(2): 142-152.

4. Tamowicz B, Mikstacki A, Kalinowska M, et al. Analysis of Causes for Resuscitation Ambulance Calls in 2005 and 2006. Nowiny Lekarskie. 2008; 6(77): 436-445.

5. Andrzejewski M, Kopański Z, Kopański G. The assessment of the functioning of Medical Rescue Teams - selected examples. Journal of Clinical Healthcare. 2015; 3.

6. Timler D, Szarpak Ł, Madziała M. Retrospective Analysis of Intervention Medical Rescue Teams Person Over the Age of 65 Years of Age. Acta Universitatis Lodziensis Folia Oeconomica. 2013; 297: 237-245. 